\title{
Médiévales
}

Langues, Textes, Histoire

60 | printemps 2011

La fitna

\section{Corinne BECK, Les Eaux et forêts en Bourgogne ducale (vers 1350-vers 1480). Société et biodiversité, Paris, L'Harmattan, 2008, 479 p.}

Didier Boisseuil

\section{OpenEdition}

1 Journals

Édition électronique

URL : https://journals.openedition.org/medievales/6228

DOI : $10.4000 /$ medievales. 6228

ISSN : 1777-5892

Éditeur

Presses universitaires de Vincennes

Édition imprimée

Date de publication : 30 juin 2011

Pagination : 207-209

ISBN : 978-2-84292-273-3

ISSN : 0751-2708

Référence électronique

Didier Boisseuil, «Corinne веск, Les Eaux et forêts en Bourgogne ducale (vers 1350-vers 1480). Société et biodiversité, Paris, L'Harmattan, 2008, 479 p. », Médiévales [En ligne], 60 | printemps 2011, mis en ligne le 30 août 2011, consulté le 22 avril 2022. URL : http://journals.openedition.org/medievales/6228 ; DOI : https://doi.org/10.4000/medievales.6228

Ce document a été généré automatiquement le 22 avril 2022

Tous droits réservés 


\title{
Corinne BECK, Les Eaux et forêts en Bourgogne ducale (vers 1350-vers 1480). Société et biodiversité, Paris, L'Harmattan, 2008, 479 p.
}

\author{
Didier Boisseuil
}

1 Le bel ouvrage de Corinne Beck porte sur l'état des écosystèmes forestier et aquatique de la Bourgogne à la fin du Moyen Âge. C'est une étude exemplaire, liée aux questionnements contemporains sur le devenir des paysages et de la biodiversité, fondée sur les travaux pluridisciplinaires les plus récents (dont les principales approches sont rappelées dès les premières pages). L'étude vise d'abord à analyser les procédés mis en œuvre par les hommes des $\mathrm{XIV}^{\mathrm{e}}$ et $\mathrm{XV}^{\mathrm{e}}$ siècles pour exploiter les ressources végétales et animales; elle précise aussi l'impact des interventions humaines sur les milieux environnementaux (révélant ainsi leur "vulnérabilité») et esquisse les comportements de ces mêmes milieux à la fin du Moyen Âge, leur évolution. L'enquête s'appuie essentiellement sur le comportement d'acteurs remarquables, le duc de Bourgogne et ses agents, entre 1350 et 1480 . Soucieux de préserver et de tirer profit des droits qu'ils détenaient sur les eaux et forêts, les derniers Valois - héritiers des ducs capétiens - ont, en effet, confié l'administration de leur vaste patrimoine, portant sur de nombreuses forêts et étangs présents dans tous les bailliages du duché, à un office particulier : la Gruerie. La richesse et la qualité des fonds archivistiques de cet office (sans lacunes regrettables) autorisent une analyse fouillée et approfondie.

2 C.B. montre, tout d'abord, l'ampleur des ressources utilisées : la composition des forêts - où semble dominer le chêne -, la grande diversité de la faune chassée ou pêchée. Surtout, elle insiste sur l'ancienneté des étangs, bien antérieurs à la "grande dépression » de la fin du Moyen Âge, et qui furent essentiellement conçus pour faciliter l'approvisionnement piscicole, avant même leur usage industriel. C.B. détaille aussi les caractéristiques du personnel de la Gruerie. À côté de l'officier principal le Gruyer - qui 
est un courtisan, néanmoins compétent - œuvrent de nombreux agents qui représentent plus du quart des serviteurs du duc. Qualifiés, ils sont gagés et tendent à former un personnel stable au point d'apparaître comme des «professionnels ». Ils gèrent le patrimoine du duc, réparent les infrastructures (principalement des étangs) et jugent les délits ou les litiges, dans une conjoncture difficile (épidémies, guerres et probable dégradation climatique) qui rendent peu aisées leurs interventions.

C.B. s'attarde ensuite longuement sur l'exploitation de la forêt, en traçant au préalable les liites de son enquête. Elle souligne combien les espaces forestiers ont fait l'objet d'une utilisation maximale (tant les hautes futaies que les taillis), qu'ils ont été gérés avec savoir-faire pour produire du bois d'œuvre ou de chauffe, des zones de pâturages ou de cueillette (destinées principalement aux communautés rurales) et des réserves de chasse, mais que, sous la pression des besoins financiers du prince, les forêts ont été, de plus en plus souvent, exploitées à des fins commerciales, entraînant des évolutions dans la façon de mettre en valeur et de renouveler, de façon satisfaisante et durable, les bois (nouvelles modalités de coupes, prémisses d'une forme de sylviculture). Il est difficile de savoir si cette nouvelle orientation économique a entraîné une surexploitation des zones sylvicoles, mais il est certain que, dans de la seconde moitié $\mathrm{du} \mathrm{Xv}^{\mathrm{e}}$ siècle, elle a suscité des conflits nouveaux avec les communautés rurales qui furent contraintes de défendre, face au pouvoir, leurs droits traditionnels.

4 Les comptes de la Gruerie révèlent aussi que les paysans utilisaient intensément les forêts et qu'ils étaient les principaux responsables des délits condamnés, en commettant des coupes de bois illicites, du braconnage, en laissant divaguer leur bétail au-delà des espaces consentis à la paissance. Ils empiétèrent peu, en revanche, sur le domaine piscicole. Car le prince s'est réservé un contrôle direct et étroit sur la pêche et les étangs, concédant seulement avec parcimonie quelques droits de pêcherie sur les cours d'eau. C.B., dans une remarquable deuxième partie, dresse un portrait exemplaire des activités piscicoles et de la gestion des étangs. La pêche est, pour le duc, une activité nécessaire - indispensable à l'approvisionnement de sa table - et surtout lucrative : la vente de poisson, principalement les carpes, constitue des revenus de plus en plus appréciables, bien qu'erratiques, pour le Trésor, dès la fin du XIve siècle. C.B. détaille les caractéristiques des plans d'eau bourguignons, les principaux traits des écosystèmes en zone humide. Elle met en avant l'importance de coûteux travaux d'entretien (construction de retenues, vidage et labourage des fonds asséchés), les pratiques piscicoles et le rôle d'une main-d'œuvre qualifiée, particulièrement mobile. Elle esquisse une progressive évolution dans la gestion des étangs, en suggérant l'apparition de bassins destinés exclusivement à l'alevinage des carpes (opération délicate) et observe des écarts de production importants entre les différents étangs à l'intérieur du duché. Surtout, face à la concurrence des marchés et aux difficultés d'entretien, C.B. met en lumière le rôle croissant des marchands qui, dans la seconde moitié du $\mathrm{Xv}^{\mathrm{e}}$ siècle, prirent en location la gestion des étangs, à la suite de l'amodiation générale décidée par Philippe le Bon en 1441-1443. Leur action fut néfaste, car intéressés par des profits rapides, ils n'entretinrent pas les plans d'eau qui en pâtirent. Plusieurs d'entre eux durent même être abandonnés par la suite.

C.B. achève son étude en dressant un aperçu des principales activités cynégétiques. Car, la chasse, sur les terres du duc, fut essentiellement l'affaire du prince et de la Gruerie; elle fut confiée, le plus souvent, à des chasseurs professionnels. Elle visait principalement quelques prédateurs : les loups tout d'abord, les loutres ensuite (qui se 
nourrissaient de poissons), puis les rapaces nuisibles (aigles, busards, etc.) ; les oiseaux affaitables (faucons, éperviers, autours) étant capturés pour la chasse du duc. S'appuyant sur des données statistiques, C.B. suggère combien l'abattage systématique des loups, malgré leur dangerosité limitée, a réduit considérablement leur présence dans les forêts bourguignonnes, alors que les loutres, également pourchassées, paraissent avoir mieux résisté. À propos des chasses organisées par la vénerie ducale principalement à l'époque de Philippe le Bon - C.B. souligne leur caractère fastueux et leur destination (la table princière essentiellement). Aussi, est-ce parce que la chasse était, avant tout, une activité de prestige que les ducs cherchèrent à contrôler la faune sauvage et à préserver leurs vastes espaces forestiers? Selon ce même principe, ils s'efforcèrent de créer une belle réserve pour les daims à Aisey-sur-Seine et des parcs à garenne, moins nombreux et moins étendus, cependant, que dans le domaine des Capétiens.

6 C.B. nous révèle, ainsi, combien le domaine des eaux et forêts ducal fut intensément exploité non seulement pour les besoins alimentaires et sociaux du duc et sa cour, mais aussi pour ses apports financiers: la biodiversité des espaces boisés et aquatiques constitue une source de revenus appréciable, bien qu'aléatoire, gérés par un personnel qualifié et nombreux. C.B. insiste, surtout, sur les transformations de ce domaine (dans sa composition même : faune et essences ligneuses), sur l'évolution des comportements des différents acteurs, qu'elle impute, pour partie, aux exigences commerciales. L'entrée de certaines productions (bois, poissons) dans "l'économie de marché» entraîne des façons nouvelles d'envisager le patrimoine ducal, de le gérer et de le façonner, sans pour autant que cela aboutisse à de francs succès. C.B. montre ainsi les limites des entreprises de la Gruerie : les balbutiements d'une forme de sylviculture et surtout les échecs d'une pisciculture qui butte sur un seuil technique, l'incapacité à maîtriser les processus biologiques c'est-à-dire les conditions de l'alevinage. 